\title{
A Comparison of Probabilistic Reasoning in Psychology Undergraduates in Italy and Spain: Seeking Cross-national Evidence
}

\author{
Mirian Agus ${ }^{1 *}$, Maribel Peró-Cebollero ${ }^{2}$, Joan Guàrdia-Olmos ${ }^{2}$, Eliano Pessa ${ }^{3}$, Rita Figus ${ }^{1}$, \\ Maria Pietronilla Penna ${ }^{1}$ \\ ${ }^{1}$ Department of Pedagogy, Psychology, Philosophy - Faculty of Humanistic Studies, University of Cagliari, ITALY \\ 2 Department of Social and Quantitative Psychology, Faculty of Psychology, University of Barcelona, SPAIN \\ ${ }^{3}$ Department of Brain and Behavioural Sciences, University of Pavia, ITALY
}

Received 12 November 2018 - Revised 4 April 2019 - Accepted 9 April 2019

\begin{abstract}
A cross-national comparison between Italy and Spain was conducted on probabilistic reasoning performance presented in verbal-numerical and graphical-pictorial formats. This study investigated the similarities and differences in Psychology undergraduates in these two countries (Italy $n=290$; Spain $n=130$ ) and attempted to identify aspects that might enhance the probability of a student belonging to one country. The findings underscored that Spanish students had higher levels of visuospatial abilities, more positive attitudes toward statistics, lower statistical anxiety, and higher confidence in the correctness of their responses. Additionally, they gave a higher number of correct responses to problems presented in a verbal-numerical format. These data suggest interesting insights and highlight the interactions among multiple layers of variables at the collective, contextual, and individual levels.
\end{abstract}

Keywords: probabilistic reasoning, abilities, attitudes, anxiety, confidence

\section{INTRODUCTION}

Many authors have attempted to examine the characteristics, similarities and dissimilarities in educational achievement in European countries (Causa \& Chapuis, 2010; Fuchs \& Wößmann, 2007; Hamilton, 2009; Oppedisano \& Turati, 2015). In particular, many research studies have analyzed European countries in relation to PISA (Program for International Student Assessment) and OECD (Organization for Economic Cooperation and Development) data, in order to identify factors that might affect economic and educational development and achievements (Demir, Kiliç, \& Ünal, 2010; Ferrera Cordero, Cebada Crespo, Chaparro Pedraja, \& Gonzàlez, 2011).

In this work, we aimed to analyze the peculiarities of Italian and Spanish Psychology undergraduates in relation to a specific field of students' ability, probabilistic reasoning applied in uncertain conditions, in order to highlight cross-national evidences useful to distinguish and predict the student's membership to Italy or Spain.

In relation to the features of statistical and probabilistic reasoning, it was observed that this type of reasoning denotes the ability to infer and use notions of casualness, chance and probability (Garfield \& Ben-Zvi, 2008). In the literature many authors have observed that the successful application of probabilistic reasoning requires connections between experimental and theoretical notions (Jones, 2005); this reasoning is involved in many activities in daily and academic contexts (Gal, 2005). Scholars have investigated methods to promote the understanding of probabilistic data presented in our society (Gal, 2002). Indeed, the comprehension of probability and statistics data is defined as a priority in lifelong learning for adults without any statistical knowledge (Gal \& Ograjenšek, 2017).

(C) 2019 by the authors; licensee Modestum Ltd., UK. This article is an open access article distributed under the terms and conditions of the Creative Commons Attribution License (http://creativecommons.org/licenses/by/4.0/). \mirian.agus@unica.it (*Correspondence) $\square$ mpero@ub.edu $\square$ jguardia@ub.edu $\square$ eliano.pessa@unipv.it \riffy7@gmail.com $\$ penna@unica.it 


\section{Contribution of this paper to the literature}

- Cross-national comparison between Italy and Spain, seeking similarities and differences in Psychology undergraduates. These students belong to countries in the European Higher Education Area (EHEA) and are characterized by both common and different aspects.

- Identifying aspects that might enhance the probability of a student belonging to Italy and Spain. We focused on the educational experiences in these two European countries, linking the results with data highlighted by the PISA surveys.

- Applying probabilistic reasoning in verbal-numerical and graphical-pictorial formats. An innovative aspect of this work was the evaluation of these relationships in undergraduates in social sciences who had not previously studied statistics, in which the effect of graphical facilitation versus graphical impediment could assume specific features. Furthermore, in previous studies these dimensions were evaluated in different ways, separating Italian and Spanish students.

\section{A Cross-national Approach in the Study of Probabilistic Reasoning}

Regarding these aspects, the assessment of probabilistic reasoning is a relevant matter of interest for cognitive scientists, but, to the best of our knowledge, it is usually not investigated in a cross-national approach. Actually the assessment of countries' peculiarities has been focused in many fields, more generally than probabilistic reasoning. In the case of Italy and Spain specifically, some authors have compared students' competences in these countries, using the PISA assessments, with regard to dimensions such as Science and Mathematics achievement results (Agasisti \& Cordero-Ferrera, 2013; Causa \& Chapuis, 2010). They highlighted that the scores obtained by Italian students in these topics were lower than those of Spanish students, in both the 2012 and the 2015 PISA assessments (Agasisti \& Cordero-Ferrera, 2013; Kastberg, Ying Chan, \& Murray, 2016).

This cross-national comparison is interesting because Italy and Spain are two countries with similarities in terms of customs, health, and levels of educational attainment (Agasisti \& Cordero-Ferrera, 2013). Both countries are placed at the bottom of the EU rankings in relation to educational achievement. However, Italy and Spain show similar values in relation to the influence of parental background on students' secondary achievement (Causa \& Chapuis, 2010), which is below the average of OECD countries. Furthermore, these countries have multiple layers of government, which are characterized by strong local and regional authorities, with wide-ranging functions and powers (Giordano \& Roller, 2003). In both countries, a regional and sub-national devolution has created some unbalanced structures of local government.

Despite decentralization tendencies in both countries being very strong, school autonomy differs in Italy and Spain. In Spain, schools have greater autonomy in the management of educational institutions, and in the selection of teaching and in management than do schools in Italy, where the educational system is typically "centralized" (Agasisti \& Cordero-Ferrera, 2013; Oppedisano \& Turati, 2015).

Additionally, most schools in Italy are public (in general, few students, approximately $4 \%$, attend private schools). If private schools are present, they mostly have religious features (Agasisti \& Pérez-Esparrells, 2010). Conversely, in Spain, the regional government provides more support for private schools (Agasisti \& CorderoFerrera, 2013).

Another relevant feature of these countries is the organization of the system of secondary schools. In Spain, there is only one school where students study (unified) for up to 16 years ("Spain: Overview - Eurydice," 2017). In Italy, the school differs from the age of 14 years, on depending on the chosen institute (comprehensive, vocational or technical). For each institute, the subjects taught might be quite different, emphasizing specific areas (Humanistic, Mathematic, Economic, Arts). A further peculiarity of Italy and Spain is that Spanish students might also be admitted to a university if they participate in a higher-level training cycle. In this case, they arrive at the university at a higher age.

Concerning the entrance selection tests at universities, it is notable that in Italy and Spain they are regulated by specific national guidelines. Precisely, in Spain the entry tests are unified at the regional level; the questions are related to the topics studied in the previous last two years and there are different questions related to each common matter coursed during the bachelor's degree.

In Italy, the entrance tests are devised independently by each university; the questions are based on the national ministerial school program carried out by all the students in the three last years in all higher schools. On account of this, the entrance tests are related to topics of "general culture", which are similar for the admission to different degrees. 
Referring to these multiple aspects, it might be interesting to deepen the peculiarities of these countries, considering that the potential differences between the students belonging to Italy and Spain could reasonably be inherent in a multiplicity of individual and socio-cultural dimensions.

\section{Why Study Probabilistic Reasoning in Psychology Undergraduates?}

The investigation of probabilistic reasoning in Italian and Spanish Psychology undergraduates have a specific relevance. Indeed, Lalonde and Gardner (1993) observed that the understanding of statistics and probability should be considered as the learning of a second language, specifically for undergraduates in Social Sciences and Psychology. In particular, in this last degree course, teachers have strong difficulties with sustaining statistical and probabilistic learning and in order to enable future psychologists to acknowledge the helpfulness of this subject in their curricula. In point of fact, the cognitive representation of their future career in these undergraduates is often naïve and so distant from the discerning the value of the application of probability and statistics (Chiesi \& Primi, 2009b; Guàrdia-Olmos et al., 2006). This aspect strongly contributes to the displeasure that Psychology undergraduates often have toward statistics and probabilistic issues. Guàrdia-Olmos et al. (2006) specifically observed that these troubles might be related, on the one hand, to the differences in the academic backgrounds of the undergraduates; and on the other hand, to the fact that the first-year undergraduates do not aim to find a subject based on statistics and probability in their degree course. Furthermore, Psychology undergraduates do not often feel appropriately prepared to cope with probabilistic matter, or do not meet effectively the requirements necessary to approach this subject. They are frequently afraid of having to do calculations; students commonly undertake these matters with anxiety (Guàrdia-Olmos et al., 2006; Primi \& Chiesi, 2016). These students frequently hold attitudes toward statistics that are not positive (Morsanyi, Primi, Chiesi, \& Handley, 2009; Primi \& Chiesi, 2016).

For the above-mentioned reasons, the assessment of peculiarities of Psychology undergraduates in Italy and Spain in relation to probabilistic reasoning might be an interesting perspective to find elements that could join or distinguish these countries.

\section{Which Variables Related to Probabilistic Reasoning Might Contribute to Distinguish / to Predict the Belonging of Psychology Undergraduate to Italy or Spain?}

In the literature, it has been highlighted that probabilistic reasoning performance can be related to the interaction among multiple individuals and contextual dimensions (Agus, Penna, Peró-Cebollero, Guàrdia-Olmos, \& Pessa, 2016; Agus, Peró-Cebollero, Penna, \& Guàrdia-Olmos, 2015a). Furthermore, many scholars observe that probabilistic reasoning can be applied in relation to different formats of problem presentation, for example in reference to verbal-numerical $(\mathrm{N})$ or graphical-pictorial $(\mathrm{G})$ formats. In particular, many authors have considered appropriate strategies to overcome difficulties in the application of probabilistic reasoning and have highlighted that it might be useful to use different formats for problem presentation (Yamagishi, 2003). For instance, it might be advantageous to arrange data in a graphical pictorial format, to use a frequency format for numerical information, to construct real situations for the problem solving setting, and to use appropriate phrasing (Binder, Krauss, \& Bruckmaier, 2015; Boonen, Van Wesel, Jolles, \& Van der Schoot, 2014; Brase, 2009; Brase \& Hill, 2015; Moro, Bodanza, \& Freidin, 2011; Wu, Meder, Filimon, \& Nelson, 2016).

Regarding these aspects, in this study we considered the relevance of the format of probabilistic problem presentation. Specifically, we assessed the so-called effect of "graphical facilitation", attempting to define the usefulness of probabilistic data presentation with images, graphs and tables (format G) (Moro et al., 2011; Penna, Agus, Peró-Cebollero, Guàrdia-Olmos, \& Pessa, 2014). The presentation of probabilistic problems in graphicalpictorial format might enable individuals to identify the relationships among the data, enhance problem solving, and overcome potential difficulties encountered in the evaluation of probabilities (Agus, Penna, Peró-Cebollero, Guàrdia-Olmos, et al., 2016; Brase \& Hill, 2015; Penna et al., 2014).

Our goal is to investigate whether these dimensions can differentiate individuals, predicting a student's membership in one of two countries.

The accuracy in solving probabilistic problems in the N and G formats could potentially be identified as one of the variables distinguishing the student's affiliation to either Italy or Spain. Furthermore, in line with the evaluations carried out on the PISA studies, we could also identify the numerical skills, among the variables that could potentially differentiate between the students of the two countries. Indeed, hardy mathematical abilities are strongly related to probabilistic reasoning (Fonteyne et al., 2015).

Nevertheless, from the theoretical point of view, many studies have highlighted that the performance in probabilistic reasoning can be related to a multiplicity of other individual dimensions. Among these, visuospatial abilities (Fonteyne et al., 2015), confidence in the correctness of the response (Stankov, Morony, \& Lee, 2014), 
statistical anxiety (Macher et al., 2013) and attitudes toward statistics (Bond, Perkins, \& Ramirez, 2012) are very relevant.

Visuospatial abilities in the literature were strongly related with math abilities and with performance in probabilistic problems (de Hevia, Vallar, \& Girelli, 2008; Feeney, Adams, Webber, \& Ewbank, 2004). Their implication in this type of performance is founded on the skill in representing and transfiguring symbolic and nonlinguistic data (Gardner, 1993).

Classically, among variables in the literature related to the performance in probabilistic reasoning, there is also the metacognitive dimension of confidence in the correctness of response, which showed high positive correlations with cognitive abilities (Stankov, 2013).

In addition, the application of probabilistic reasoning is often related to statistical anxiety, which denotes the tendency to experience emotional states of worry and nervousness in the application in statistical and probabilistic problems (Onwuegbuzie, 1995; Williams, 2014). Statistical anxiety may develop from mathematical anxiety (Baloglu, 2003); it might divert the student's attention from the task, thereby impeding the performance (Heckhausen \& Leppmann, 1991). It has been found to be negatively and significantly related to performance in statistics and to the achievement in probabilistic matters (Onwuegbuzie \& Seaman, 1995).

The performance in probabilistic reasoning appears to also be related to the attitudes toward statistics; this dimension denotes a composite representation related to the positive versus negative moods and evaluations about statistical subjects (Gal, Ginsburg, \& Schau, 1997). In these attitudes, it is possible to distinguish affective features, as well as cognitive and behavioral aspects. Many scholars have highlighted a significant positive correlation between the attitude toward statistics and performance in probabilistic and statistical tasks (Finney \& Schraw, 2003).

\begin{abstract}
AIMS
Focusing on the application of probabilistic reasoning in verbal-numerical and graphical-pictorial formats, this work assessed numerical and visuospatial abilities, confidence in the correctness of the response, statistical anxiety and attitudes toward statistics in order to compare outcomes in Italy and Spain. In our previous research, Psychology undergraduates in the two countries were analyzed separately. In this study, we assess whether some distinctive features might predict which students belong to one of these two countries. We consider whether there is more heterogeneity or similarity between the students of these two countries in relation to the aforementioned dimensions.
\end{abstract}

On the basis of previous studies (Agasisti \& Cordero-Ferrera, 2013; Agasisti \& Pérez-Esparrells, 2010; Giordano \& Roller, 2003; Oppedisano \& Turati, 2015), we formulated two questions of investigation:

1) Are there some aspects that characterize probabilistic reasoning in verbal-numerical and graphical-pictorial formats and their related dimensions (abilities, confidence, anxiety and attitudes) in Psychology undergraduates in Italy and Spain?

2) What dimensions differentiate Italian and Spanish Psychology undergraduates?

\title{
METHODS
}

\section{Participants}

We compared Psychology undergraduates who were assessed collectively in their first-year university course. A sample of 290 students from Italy and 130 from Spain agreed to participate in the study. There were 93 females in the Spanish group and 241 females in the Italian group. The participants had a mean age of 19.680 years $(\mathrm{sd}=$ $2.938)$ in Italy and 20.410 years $(s d=6.168)$ in Spain. The Italian undergraduates belonged to the Universities of Genoa $(n=118)$ and Milan $(n=172)$, and the Spanish students attended the University of Barcelona. Regarding education, $94.4 \%$ of the Italian students attended a comprehensive high school (called "Liceo" in Italy) and the other 5.6\% attended a technical/vocational high school (called "Istituto Tecnico" - "Istituto Professionale" in Italy); in Spain, $82.0 \%$ attended a comprehensive high school (called "Bachillerato" in Spain) and 18\% attended a technical/vocational high school (called "Ciclo Formativo de Grado Superior" - "Higher education training cycle" in Spain). The sampling was non-probabilistic; all undergraduates participated voluntarily in this study.

\section{Instruments and Procedure}

For the present study, we used instruments previously developed and validated in both countries to assess probabilistic reasoning conducted as homologous problems presented in verbal-numerical $(\mathrm{N})$ and graphicalpictorial (G) formats (Agus, Penna, Peró-Cebollero, \& Guàrdia-Olmos, 2016; Agus, Peró-Cebollero, Penna, \& 
Table 1. Comparisons between the Italian and Spanish Psychology undergraduates in relation to socio-demographic variables

\begin{tabular}{|c|c|c|c|c|}
\hline & & Spain & Italy & $\begin{array}{c}\text { Statistic } \\
\text { Df ( } p \text { value) } \\
\text { Effect Size }\end{array}$ \\
\hline \multirow{2}{*}{ Gender } & Males fr\% & $28.7 \%$ & $16.3 \%$ & \multirow{2}{*}{$\begin{array}{c}\chi^{2}=8.465 \\
\mathrm{df}=1(p=.004)^{\star \star} \\
\text { Cramer's V }=.142\end{array}$} \\
\hline & Females fr\% & $71.3 \%$ & $83.7 \%$ & \\
\hline \multirow{2}{*}{$\begin{array}{l}\text { High school } \\
\text { attended }\end{array}$} & Comprehensive high school fr\% & $82.0 \%$ & $94.4 \%$ & \multirow{2}{*}{$\begin{array}{c}\chi^{2}=15.465 \\
d f=1(p=.0001)^{\star \star} \\
\text { Cramer's V }=.197\end{array}$} \\
\hline & Technical/vocational high school fr\% & $18.0 \%$ & $5.6 \%$ & \\
\hline Age & Mean (sd) & $20.410(\mathrm{sd}=6.168)$ & $19.680(\mathrm{sd}=2.938)$ & $\begin{array}{c}t=1.286 \\
d f=156.03(p=.200) \\
\text { Hedges' } g=.173\end{array}$ \\
\hline
\end{tabular}

Guàrdia-Olmos, 2015b). The probabilistic problems were administered in reversed order and sequence to avoid always presenting the items in the same position.

The protocol included other sections investigating further relevant dimensions that were identified in the literature as affecting probabilistic reasoning: statistical anxiety, attitudes toward statistics, numerical and visuospatial abilities, and confidence in the correctness of the response.

Specifically, statistical anxiety was assessed with the Statistical Anxiety Scale Questionnaire (SAS) (Chiesi, Primi, \& Carmona, 2011; Vigil-Colet, Lorenzo-Seva, \& Condon, 2008), which included the dimensions of Examination, Asking for help, and Interpretation.

The attitudes toward statistics were investigated by the Survey of Attitudes Toward Statistics (SATS-28) (Chiesi \& Primi, 2009a; Chiesi et al., 2011; Schau, Stevens, Dauphinee, \& Del Vecchio, 1995), which is composed of four scales (Affect, Value, Difficulty, and Cognitive competence).

Confidence in the correctness of a given response was assessed by a Likert Scale with five options ("How confident are you in the correctness of your response?" from 1 - not at all confident to 5 - extremely confident) (Agus, Penna, Peró-Cebollero, \& Guàrdia-Olmos, 2016; Jackson, Kleitman, Howie, \& Stankov, 2016).

Furthermore, to assess individual abilities, the Primary Mental Abilities Questionnaire (PMA) (Thurstone \& Thurstone, 1981, 1987) was administered, specifically the subscales referring to numerical and visuospatial abilities.

All questionnaires were presented to each student in the student's native language using the validated versions for the Spanish and Italian groups.

The questionnaires were administered without any time limit (except for PMA, for which the guidelines were followed in relation to the administration of time limits).

To participate in this study, the undergraduates were requested to have no specific knowledge about statistics. All participants gave their informed consent to participate in the research.

The data analyses were conducted with IBM SPSS (release 22) software.

\section{RESULTS}

To assess and compare the undergraduates in Spain and Italy, we evaluated two groups of students in relation to the assessed dimensions. On the basis of features of the examined variables, we applied non-parametric (Chi square or Wilcoxon's Test) or parametric statistics (Student's t).

The socio-demographic variables were compared (gender, high school attended, age) (see Table 1).

There was a significant difference between Italian and Spanish undergraduates in terms of gender. Specifically, in Spain, there was a larger number of males than in Italy. Furthermore, we can observe that in Spain, a larger number of undergraduates attended technical high schools than in Italy. However, in relation to the variable "age" there was no significant difference between the two countries (see Table 1).

Comparisons between Spanish and Italian undergraduates were also performed in relation to the other dimensions investigated: numerical and visuospatial abilities (PMA), statistical anxiety (SAS), and attitudes toward statistics (SATS-28) (Table 2). 
Table 2. Comparisons between the Italian and Spanish Psychology undergraduates in abilities (PMA), statistical anxiety (SAS) and attitudes toward statistics (SATS)

\begin{tabular}{|c|c|c|c|c|c|}
\hline & & $\begin{array}{l}\text { Spain } \\
\text { M (sd) }\end{array}$ & $\begin{array}{c}\text { Italy } \\
\text { M (sd) }\end{array}$ & $\begin{array}{c}t \text { test } \\
\text { df ( } p \text { value) } \\
\end{array}$ & $\begin{array}{l}\text { Effect Size } \\
\text { Hedges' g }\end{array}$ \\
\hline \multirow{2}{*}{ PMA } & Visuospatial ability & $23.938(11.771)$ & $20.927(10.574)$ & $t=2.597 \mathrm{df}=418(\mathrm{p}=.010)^{\star \star}$ & .274 \\
\hline & Numerical ability & $17.030(6.314)$ & $18.045(6.660)$ & $t=-1.464 d f=414(p=.144)$ & .154 \\
\hline \multirow{3}{*}{ SAS } & Examination & $31.110(6.136)$ & $32.940(6.965)$ & $\mathrm{t}=-2.461 \mathrm{df}=345(\mathrm{p}=.014)^{\star}$ & .272 \\
\hline & Interpretation & $17.204(5.150)$ & $18.268(6.256)$ & $\mathrm{t}=-1.710 \mathrm{df}=345(\mathrm{p}=.088)$ & .179 \\
\hline & Help & $16.141(7.219)$ & $17.889(6.804)$ & $t=-2.250 \mathrm{df}=343(p=.025)^{*}$ & .252 \\
\hline \multirow{4}{*}{ SATS } & Affect & $22.038(4.785)$ & $18.054(5.532)$ & $\mathrm{t}=7.056 \mathrm{df}=403(\mathrm{p}=.0001)^{\star *}$ & .749 \\
\hline & Competence & $28.430(4.889)$ & $23.175(5.720)$ & $\mathrm{t}=9.026 \mathrm{df}=402(\mathrm{p}=.0001)^{\star \star}$ & .959 \\
\hline & Value & $47.123(9.285)$ & $41.194(9.682)$ & $t=5.822 d f=401(p=.0001)^{\star *}$ & .620 \\
\hline & Difficulty & $27.200(5.735)$ & $24.095(5.959)$ & $\mathrm{t}=4.940 \mathrm{df}=400(\mathrm{p}=.0001)^{\star \star}$ & .527 \\
\hline
\end{tabular}

${ }^{*} p<.05 * * p<.001$

Table 3. Comparisons between the Italian and Spanish Psychology undergraduates in probabilistic reasoning and confidence in $\mathrm{N}$ and $\mathrm{G}$ problem formats

\begin{tabular}{|c|c|c|c|c|}
\hline & Spain & Italy & $\begin{array}{l}\text { Wilcoxon's W } \\
\text { (p value) }\end{array}$ & $\begin{array}{c}\text { Effect Size } \\
r\end{array}$ \\
\hline $\begin{array}{l}\text { PROBABILISTIC REASONING } \\
\text { N FORMAT }\end{array}$ & $\begin{array}{c}M=2.007 \\
(s d=1.470) \\
M d n=2.000\end{array}$ & $\begin{array}{c}M=1.737 \\
(s d=1.5763) \\
M d n=1.000\end{array}$ & $\begin{array}{l}58821.500 \\
(p=.048)^{\star}\end{array}$ & .096 \\
\hline $\begin{array}{l}\text { PROBABILISTIC REASONING } \\
\text { G FORMAT }\end{array}$ & $\begin{array}{c}M=2.615 \\
(s d=1.354) \\
M d n=2.000\end{array}$ & $\begin{array}{c}M=2.417 \\
(s d=1.574) \\
M d n=2.000\end{array}$ & $\begin{array}{c}59831.500 \\
(p=.283)\end{array}$ & .052 \\
\hline $\begin{array}{l}\text { CONFIDENCE } \\
\text { N FORMAT }\end{array}$ & $\begin{array}{c}M=3.584 \\
(s d=.901) \\
M d n=3.600\end{array}$ & $\begin{array}{c}M=2.962 \\
(s d=1.015) \\
M d n=3.000\end{array}$ & $\begin{array}{l}39512.500 \\
(p=.0001)^{\star *}\end{array}$ & .277 \\
\hline $\begin{array}{l}\text { CONFIDENCE } \\
\text { G FORMAT }\end{array}$ & $\begin{array}{c}M=3.731 \\
(s d=.813) \\
M d n=3.800\end{array}$ & $\begin{array}{c}M=2.961 \\
(s d=1.006) \\
M d n=3.000\end{array}$ & $\begin{array}{l}41184.500 \\
(p=.0001)^{\star *}\end{array}$ & .347 \\
\hline
\end{tabular}

${ }^{*} p<.05^{* *} p<.001$

Student's t tests were used for each comparison to assess homoscedasticity. The results highlighted a significant difference in visuospatial abilities, in which the Spanish undergraduates obtained scores that were significantly higher than those of the Italian students. The difference was not found for numerical ability, in which the scores in the two countries were similar (Table 2).

For statistical anxiety, significant differences in Examination and Help were found; Italian undergraduates had higher scores. The SAS dimension Interpretation was not significantly different between the two countries.

Regarding Attitudes toward statistics, we observed significant differences in the four SATS scales (Affect, Competence, Value, Difficulty): the Spanish students showed better aptitude toward statistics and had higher scores than the Italian students did (Table 2).

The two countries were compared in terms of the number of correct responses given in N and G formats (Table 3). We applied the Wilcoxon's W test, which highlighted a significant difference in the correct responses given in the $\mathrm{N}$ format in the two countries. The Spanish undergraduates provided a higher number of correct responses in the verbal-numerical format of problem presentation $(\mathrm{N})$ than the Italian students did.

Furthermore, we observed a significant difference between the two countries in confidence in the correctness of the response just given for probabilistic reasoning problems. In both formats $(\mathrm{N}$ and $\mathrm{G})$, the Spanish students showed significantly higher levels of confidence than the Italian students did (Table 3).

Subsequently, a Hierarchical Binomial Logistic Regression was applied to identify whether the variables examined were useful in predicting the dichotomous variable of students' country (Spain $=0$; Italy $=1$ ) (Christensen, 1997). The variables included in the model as predictors were: demographic data (age, gender, type of high school attended), accuracy in probabilistic reasoning in verbal-numerical (N) and graphical-pictorial (G) problems, confidence in the correctness of the response, numerical and visuospatial abilities, statistical anxiety, and attitudes toward statistics.

The goodness-of-fit for our model was assessed by the Hosmer-Lemeshow test (good fit is defined as $\mathrm{p}>.05$ ). The comprehensive predictive capacity was evaluated through the Nagelkerke's Pseudo $\mathrm{R}^{2}$ coefficient, and the global accuracy of the classification was related to the percentage of undergraduates correctly predicted by the 
Table 4. Hierarchical Binomial Logistic Regression - Dependent Variable: Country (Spain=0; Italy=1)

\begin{tabular}{|c|c|c|c|c|c|c|}
\hline Step & Nagelkerke's $\mathbf{R}^{2}$ & Predictors & B & OR & SE & Wald ( $p$ value) \\
\hline \multirow{6}{*}{ Last $6^{\text {th }}$} & \multirow{6}{*}{.453} & Age & .086 & 1.089 & .038 & $5.134(p=.023)^{\star}$ \\
\hline & & Type of high school & -1.648 & .192 & .502 & $10.796(p=.001)^{\star \star}$ \\
\hline & & SATS Affect & -.077 & .926 & .037 & $4.377(p=.036)^{\star}$ \\
\hline & & SATS Competence & -.129 & .879 & .035 & $13.753(p=.0001)^{\star \star}$ \\
\hline & & G correct responses & .684 & 1.981 & .133 & $26.396(p=.0001)^{\star \star}$ \\
\hline & & G Confidence & -1.146 & .318 & .200 & $32.949(p=.0001)^{\star \star}$ \\
\hline
\end{tabular}

regression model in their country. The coefficients related to each independent explanatory variable were expressed as an odds ratio (OR) that defines the association between the probability of an event happening in one country and the probability of it happening in the other country. The OR has a value above 1 when the explanatory variable increases the probability of belonging to the group defined as 1 in the criterion variable (in our case, Italy). The OR has a value between 0 and 1 when the explanatory variable reduces the probability of such an event (Christensen, 1997). The OR can be interpreted as the effect of one unit of change in the explanatory variable in the predicted dependent variable when other variables in the model are held constant.

The significant explanatory variables were identified in the sixth and final step of this Hierarchical Binomial Logistic Regression. The Hosmer-Lemeshow Index supported the goodness-of-fit our model (Chi Square= 4.036; $\mathrm{df}=8 ; \mathrm{p}=.854)$. In the last step, the global percentage of students correctly predicted as belonging to their country was $78.1 \%$ (Spain $69.5 \%$; Italy $83.6 \%$ ).

In relation to the socio-demographic explanatory variables, we observed that higher age was related to the probability of belonging to the Italian undergraduates $(\mathrm{OR}=1.089)$. An increase of one unit of age increased the probability to belonging to the Italian group by $8 \%$. The undergraduates who had attended technical high schools had lower probabilities of belonging to the Italian subgroup $(\mathrm{OR}=.192)$. Indeed, it was observed that many of the Italian undergraduates attended a comprehensive high school. In relation to the attitudes toward statistics, the students with lower levels of SATS Affect had higher probabilities of belonging to the Italian group (OR=.926). Furthermore, the undergraduates with lower scores on the SATS Competence had higher probabilities of belonging to the Italian subgroup $(\mathrm{OR}=.879)$. These aspects are consistent with previous results that highlighted the higher scores on attitudes toward statistics in Spanish students. Concerning probabilistic reasoning, students who solved a larger number of problems in the $G$ format had a greater probability of belonging to the Italian subgroup $(\mathrm{OR}=1.981)$. In this regard, it might be relevant to note that the OR refers to the effect of explanatory variable on the dummy variable when other variables in the model are held constant. Thus, this finding suggests a stronger effect of graphical facilitation in Italian undergraduates than in Spanish undergraduates. Furthermore, subjects who had low levels of confidence in problems in the $\mathrm{G}$ format had a higher probability of belonging to the Italian subgroup $(\mathrm{OR}=.318)$. Italian students showed lower levels of confidence than Spanish students did.

\section{DISCUSSION}

In this work, we evaluated probabilistic reasoning performance by Psychology undergraduates in Italy and Spain and aimed to identify cross-national differences and similarities between these countries. In the previous phase of research, we paid attention to aspects that affected probabilistic reasoning and compared achievement on problems presented in verbal-numerical and graphical-pictorial formats (Agus, Penna, Peró-Cebollero, GuàrdiaOlmos, et al., 2016). Formerly, these assessments were applied separately for Italian and Spanish Psychology undergraduates, and an explicit comparison between the dimensions investigated in these two European countries was lacking (Agus, Peró-Cebollero, et al., 2015a). Here, we analyzed potential determinants and characterized features of belonging to these two European countries in terms of probabilistic reasoning in verbal-numerical and graphical-pictorial formats.

First, a comparison between the values obtained in two countries was conducted. Then, with regard to explanatory variables, we applied a Hierarchical Binomial Logistic Regression that included some of the variables that have been most frequently identified as influential in probabilistic reasoning in subjects without statistical knowledge. Among these dimensions from the literature, we selected abilities (numerical and visuospatial), statistical anxiety, attitudes toward statistics, and confidence in the correctness of responses (Agus, Penna, PeróCebollero, Guàrdia-Olmos, et al., 2016).

The findings highlighted several common features and several distinctive aspects characterizing Italian and Spanish undergraduates in Psychology. We observed that the two countries did not diverge in relation to the mean age of undergraduates, which, conversely, differed by gender and high school attended (e.g., Italians were mostly females and had generally attended comprehensive high schools, called "Liceo" in Italy). These results are 
consistent with the typical socio-demographic characteristics of Italian undergraduates, who, specifically in the Psychology field, are mostly females and attended a comprehensive high school, as confirmed by the data of Ministry of Education and by some research (e.g., Ballarino \& Panichella, 2016; Triventi \& Trivellato, 2009).

Regarding numerical and visuospatial abilities, Spanish students had better visuospatial abilities than Italians did. Nevertheless, there were no dissimilarities in numerical abilities. Furthermore, we observed a significant difference in the Examination and Help dimensions of $S A S$, in which Italians had higher scores than Spanish students did. Other significant differences were found the dimensions of the SATS-28 (Affect, Competence, Value and Difficulty), through which we found that Spanish students had more positive attitudes toward statistics than Italians did.

Concerning probabilistic reasoning performance, Spanish students provided a higher number of correct responses to problems in the $\mathrm{N}$ format than Italians did. These results are consistent with the levels of confidence encountered, which were significantly higher in the Spanish students.

To better understand these differences, we used a Hierarchical Binary Logistic Regression to determine whether the factors behind the students' probabilistic reasoning performance were analogous in these two countries and we focused on the dimensions that might correctly predict the students' country.

Higher age was related to the probability of belonging to the Italian undergraduates. Furthermore, the undergraduates who attended technical high schools had greater probabilities of belonging to the Spanish subgroup. In relation to the attitudes toward statistics, the students with lower scores for SATS Affect had higher probabilities of belonging to the Italian group. Similarly, the undergraduates with lower scores for SATS Competence had higher probabilities of being Italians. For probabilistic reasoning, students who answered more problems correctly in the $\mathrm{G}$ format had higher probabilities of fitting into the Italian group. However, the undergraduates with low levels of confidence in the $G$ format had a higher probability of belonging to the Italian group.

These outcomes are consistent with the literature, which showed that Italians were more reactive to anxietyprovoking conditions and that they had lower visuospatial abilities and lower confidence than the Spanish did in probabilistic reasoning performance (Agus, Peró-Cebollero, et al., 2015a).

To understand these results, we might refer to the specific features of the scholastic systems in these countries. In the last PISA 2015 assessment (http://www.oecd.org/pisa/PISA2015-Students-Well-being-Country-noteItaly.pdf; http:/ / www.oecd.org/pisa/PISA2015-Students-Well-being-Country-note-Spain.pdf), it was established that Italians had higher levels of anxiety than Spanish students did. In the literature, it has been highlighted that this non-cognitive dimension is strongly related to reasoning, along with attitudes and confidence. These aspects might intensely affect the application of correct solution strategies and enhance or hamper performance (Bond et al., 2012; Gal, Ginsburg, \& Schau, 1997; Lai et al., 2016; Richardson, Abraham, \& Bond, 2012).

Furthermore, the PISA 2015 assessments allowed us to consider performance in mathematics and science. Comparing Italy and Spain, we can observe better results among Spanish students (http://www.compareyourcountry.org/pisa/country/esp10?lg=en), who have higher scores in science, mathematics, and reading skills. Additionally, focusing on specific categories of students, such as top performers, we can find better scores among Spanish students than among Italian students (http:/ / www.compareyourcountry.org/pisa/country/esp10?lg=en).

Consistent with these PISA outcomes, we might assume that the worse results in our Italian undergraduates may be related to the strong differences in the mathematics and science curricula in different secondary schools (comprehensive schools, technical and vocational schools). These differentiated curricula begin in Italy at 14 years of age. The students attending different schools do not study the same programs in terms of mathematics and probability, which may have led to substantial differences in the students' performance (Agasisti \& CorderoFerrera, 2013) and probabilistic reasoning. These outcomes are consistent with the literature, which found a considerable difference in PISA achievement scores in relation to the type of secondary school attended (Agasisti \& Cordero-Ferrera, 2013). Conversely, in Spain, the curricula among different high schools is differentiated two years later (at 16 years), giving all students similar preparation in mathematics, science, reading, and other disciplines (Calet \& Dumitrache, 2016; López-Justicia, Hernández, Fernández Jiménez, Polo Sánchez, \& López Chacón, 2008).

Among the aspects that potentially affect undergraduates' performance, it is important to consider the system of entrance to university, which is different in Italy and Spain. In Italy, each university manages the entrance examination to its courses at the local level with different tests and by considering the scores obtained by students on their final high school exam. In Spain, the entrance tests are unified at the regional level (University Entrance Examination - P.A.U.), guaranteeing a more impartial evaluation of the students' skills. This aspect may impact the students' performance and subsequent careers (Calet \& Dumitrache, 2016).

From another point of view, the results of our evaluations might be related to the critical situation in the Italian school system, which has suffered a climate of strong political instability in recent decades. The Italians have 
experienced a contraction in investments through different reforms aimed at promoting a review of spending. All of these reforms have not been fully implemented. However, there are signs in school organizations, institutional programs, and ordinances of every scholastic degree. These reforms have been erased by political successors in recent years, leaving the scholastic institutions with strong uncertainty (Azzolini \& Vergolini, 2014). These unfinished reforms have been conceived as modifying a malfunctioning state, overcoming criticisms, modernizing an old educational system, and attempting to match the requirements of the working world. Nevertheless, the actual results of these processes might be considered unsatisfactory (Giordano \& Roller, 2003). Our findings are consistent with the results of Agasisti and colleagues (2013), who observed strong differences among different areas of Italy. This finding suggests the utility of enhancing the organization and monitoring education, which should be tailored to the affected students' needs (Agasisti \& Cordero-Ferrera, 2013). In the literature, several scholars have studied the educational features of European countries, attempting to identify between-country dissimilarities and factors that affect inequalities in achievement. Martins and colleague (2010) noticed that in Spain, mathematics students' achievement was strongly related to the student's family socioeconomic background, whereas in Italy, it was more closely related to the school system composition (i.e., policies, regulations, funding, resource allocations, school facilities, human resources, staffing, teaching resources, and learning materials) (Martins \& Veiga, 2010). This fact might be associated with the stronger effect of familial and small-group variables in Spanish students' achievement than in the achievement of Italian students. We might speculate that in Italy, the "centralized" approach to education entailed a stronger role of organizational variables and a robust load on the achievement of the type of school attended that was stronger than in Spain. This aspect might suggest the utility of better understanding the relevance of the design of educational reforms to enhance efficiency and equity and their impact in students' achievement.

Finally, we must note that this work had several limitations. The participants were recruited from a small number of universities. Furthermore, few students voluntarily participated in the research in those universities (in the absence of specific rewards). Consequently, regarding the participants, there is a notable difference in the size of the Italian and Spanish samples. Nevertheless, despite the numerical disparity between the groups, we thought we could carry out the study by virtue of some considerations. Some authors (e.g. Herrera \& Gómez, 2008) have compared the estimations and the indexes deriving from the application of logistic regression in relation to groups that are very different in their size; specifically, they highlighted the opportunity for obtaining similar estimates even in the case in which a group is numerically five times greater than another. Coherently, as regards the unequal number of males and females in the Italian and in the Spanish group, this fact too can be considered in relation to the same reflection. Furthermore, we considered also that in the Italian and Spanish population of undergraduates in Psychology, there is higher number of female-gendered students (these data were confirmed by the Ministry of Education in Italy - http://ustat.miur.it/media/1116/notiziario-statistico-2017-1.pdf - and Spain https://www.educacion.gob.es/educabase/tabla.do?path=/Universitaria/Alumnado/Estadistica/2015-2016/1 GradoCiclo/CapituloI/10/\&file=RD14_mat_11.px\&type=pcaxis\&L=0\%3C/font\%3E). Moreover, the assessment of these data was supported by the fact that the variable of gender is not relevant in relation to our assessment, because there is not a differential behavior between males and females in the degree course and in relation to the dimensions inquired in this study (Agus, Peró-Cebollero, et al., 2015a).

Among the limitations, we can include the lack of consideration of some relevant dimensions that potentially affect achievement in probabilistic reasoning. Reading comprehension, also assessed in the PISA surveys, might have a relevant role in the understanding of probabilistic problems (Wells, Christiansen, Race, Acheson, \& MacDonald, 2009). We might consider including the assessment of this dimension in the following phases of this investigation. It might be useful to reflect on these aspects to depict a more comprehensive assessment of the many dimensions that affect the understanding of probabilities and the specific attributes of Spanish and Italian students.

In relation to the limits of this research, we might consider also the fact that only the data relating to two European countries have been examined and compared. In the future, we hope for the possibility of continuing the study, extending the evaluations and comparisons to other European countries, in order to better define the specificities and characteristics of the different courses, as well as their influences on student education.

Nevertheless, these findings suggest the need for reflection on the characteristics of the national school systems and on the impact of policies and organizations on students' achievements and attitudes (Causa \& Chapuis, 2010). We might speculate that the best-performing countries in achievement are characterized by coherence and unity of targets at the central and peripheral levels as well as by the presence of funds aimed at improving the quality of teaching (Causa \& Chapuis, 2010).

To sum up, the dimensions investigated seem more positive for the Spanish undergraduates than for Italians. It may be necessary to revise the approach to the Italian educational system to better support students in the study of probabilistic reasoning by elaborating new systems to manage the increasing complexity and to support the educational needs of populations. 
These findings can contribute to improving achievement in scientific fields resulting from the interaction among multiple layers of variables at the collective, contextual, and individual levels that may affect students' performance. These results suggest the opportunity to target specific strategies devoted to enhancing individual performance with reference to an adaptive learning approach by which we can overcome each students' difficulties in the approach to these matters (van Ginkel, Oolbekkink, Meijer, \& Verloop, 2016).

\section{ACKNOWLEDGEMENTS}

Part of the paper was written when the second author was a Visiting Professor at the University of Cagliari. Thanks to the financial support sponsored by the Sardinian Regional Government.

\section{REFERENCES}

Agasisti, T., \& Cordero-Ferrera, J. M. (2013). Educational disparities across regions: A multilevel analysis for Italy and Spain. Journal of Policy Modeling, 35(6), 1079-1102. https:/ / doi.org/10.1016/j.jpolmod.2013.07.002

Agasisti, T., \& Pérez-Esparrells, C. (2010). Comparing efficiency in a cross-country perspective: the case of Italian and Spanish state universities. Higher Education, 59(1), 85-103. https:/ / doi.org/10.1007/s10734-009-9235-8

Agus, M., Penna, M. P., Peró-Cebollero, M., \& Guàrdia-Olmos, J. (2016). Assessing Probabilistic Reasoning in Verbal-Numerical and Graphical-Pictorial Formats: An Evaluation of the Psychometric Properties of an Instrument. Eurasia Journal of Mathematics, Science \& Technology Education, 12(8), 2013-2038. https:/ / doi.org/10.12973/eurasia.2016.1265a

Agus, M., Penna, M. P., Peró-Cebollero, M., Guàrdia-Olmos, J., \& Pessa, E. (2016). Investigating the probabilistic reasoning in verbal-numerical and graphical-pictorial formats in relation to cognitive and non-cognitive dimensions: The proposal of a model. Personality and Individual Differences, 94, 44-53. https:/ / doi.org/10.1016/j.paid.2016.01.003

Agus, M., Peró-Cebollero, M., Penna, M. P., \& Guàrdia-Olmos, J. (2015a). Comparing Psychology Undergraduates' Performance in Probabilistic Reasoning under Verbal-Numerical and Graphical-Pictorial Problem Presentation Format: What is the Role of Individual and Contextual Dimensions? Eurasia Journal of Mathematics, Science \& Technology Education, 11(4), 735-750. https:/ / doi.org/10.12973/eurasia.2015.1382a

Agus, M., Peró-Cebollero, M., Penna, M. P., \& Guàrdia-Olmos, J. (2015b). Towards the development of problems comparing verbal-numerical and graphical formats in statistical reasoning. Quality and Quantity, 49(2), 691709. https:// doi.org/10.1007/s11135-014-0018-7

Azzolini, D., \& Vergolini, L. (2014). Tracking, inequality and education policy. Looking for a recipe for the Italian case. Scuola democratica, 2, 1-11. https:/ / doi.org/10.12828/77685

Ballarino, G., \& Panichella, N. (2016). Social stratification, secondary school tracking and university enrolment in Italy. Contemporary Social Science, 11(2-3), 169-182. https:/ / doi.org/10.1080/21582041.2016.1186823

Baloglu, M. (2003). Individual differences in statistics anxiety among college students. Personality and Individual Differences, 34(5), 855-865. https:/ / doi.org/10.1016/S0191-8869(02)00076-4

Binder, K., Krauss, S., \& Bruckmaier, G. (2015). Effects of visualizing statistical information - an empirical study on tree diagrams and 2 x 2 tables. Frontiers in Psychology, 6, 1-9. https:/ / doi.org/10.3389/fpsyg.2015.01186

Bond, M. E., Perkins, S. N., \& Ramirez, C. (2012). Students' perceptions of statistics: an exploration of attitudes, conceptualizations, and content knowledge of statistics. Statistics Education Research Journal, 11(2), 6-25.

Boonen, A. J. H. H., Van Wesel, F., Jolles, J., \& Van der Schoot, M. (2014). The role of visual representation type, spatial ability, and reading comprehension in word problem solving: An item-level analysis in elementary school children. International Journal of Educational Research, 68, 15-26. https:/ / doi.org/10.1016/j.ijer.2014.08.001

Brase, G. L. (2009). Pictorial representations in statistical reasoning. Applied Cognitive Psychology, 23(3), 369-381. https:/ / doi.org/10.1002/acp.1460

Brase, G. L., \& Hill, W. T. (2015). Good fences make for good neighbors but bad science: a review of what improves Bayesian reasoning and why. Frontiers in Psychology, 6, 340. https:/ / doi.org/10.3389/fpsyg.2015.00340

Calet, N., \& Dumitrache, C. G. (2016). Características de los Estudiantes de Grado de las áreas Ciencias Sociales y Salud: autoconcepto, motivación y estrategias de aprendizaje. REDU. Revista de Docencia Universitaria, 14(2), 245. https://doi.org/10.4995/redu.2016.5951

Causa, O., \& Chapuis, C. (2010). Equity in Student Achievement Across OECD Countries An Investigation of the Role of Policies. OECD Journal: Economic Studies, 5(1), 1-50. https:/ / doi.org/10.1787/19952856 
Chiesi, F., \& Primi, C. (2009a). Assessing statistics attitudes among college students: Psychometric properties of the Italian version of the Survey of Attitudes toward Statistics (SATS). Learning and Individual Differences, 19(2), 309-313. https:// doi.org/10.1016/j.lindif.2008.10.008

Chiesi, F., \& Primi, C. (2009b). Un modello sul rendimento nelle materie quantitative degli studenti di psicologia. Giornale Italiano Di Psicologia, 36(1), 161-184.

Chiesi, F., Primi, C., \& Carmona, J. (2011). Measuring Statistics Anxiety. Cross-Country Validity of the Statistical Anxiety Scale (SAS). Journal of Psychoeducational Assessment, 29(6), 559-569. https:/ / doi.org/10.1177/0734282911404985

Christensen, R. (1997). Log-linear models and logistic regression. Springer Verlag.

de Hevia, M. D., Vallar, G., \& Girelli, L. (2008). Visualizing numbers in the mind's eye: the role of visuo-spatial processes in numerical abilities. Neuroscience and Biobehavioral Reviews, 32(8), 1361-72. https:/ / doi.org/10.1016/j.neubiorev.2008.05.015

Demir, I., Kiliç, S., \& Ünal, H. (2010). Effects of students' and schools' characteristics on mathematics achievement: Findings from PISA 2006. In Procedia - Social and Behavioral Sciences (Vol. 2, pp. 3099-3103). https://doi.org/10.1016/j.sbspro.2010.03.472

Feeney, A., Adams, J., Webber, L., \& Ewbank, M. (2004). Individual differences in graphical reasoning. In A. F. Blackwell, K. Marriott, \& A. Shimojima (Eds.), Diagrammatic Representation and Inference (Vol. 2980, pp. 271285). Berlin Heidelberg: Springer. https:// doi.org/10.1007/978-3-540-25931-2_27

Ferrera Cordero, J. M., Cebada Crespo, E., Chaparro Pedraja, F., \& Gonzàlez, D. (2011). Exploring educational efficiency divergences across Spanish regions in PISA 2006. Revista de Economia Aplicada, 19(57), 117-145.

Finney, S. J., \& Schraw, G. (2003). Self-efficacy beliefs in college statistics courses. Contemporary Educational Psychology, 28(2), 161-186. https:/ / doi.org/10.1016/S0361-476X(02)00015-2

Fonteyne, L., De Fruyt, F., Dewulf, N., Duyck, W., Erauw, K., Goeminne, K., ... others. (2015). Basic mathematics test predicts statistics achievement and overall first year academic success. European Journal of Psychology of Education, 30(1), 95-118. https:/ / doi.org/10.1007/s10212-014-0230-9

Fuchs, T., \& Wößmann, L. (2007). What accounts for international differences in student performance? A reexamination using PISA data. Empirical Economics, 32(2-3), 433-464. https://doi.org/10.1007/s00181-006$0087-0$

Gal, I. (2002). Adults' statistical literacy: Meanings, components, responsibilities. International Statistical Review, 70(1), 1-25. https://doi.org/10.1111/j.1751-5823.2002.tb00336.x

Gal, I. (2005). Towards "probability literacy" for all citizens: Building blocks and instructional dilemmas. In G. A. Jones (Ed.), Exploring Probability in School (pp. 39-63). Springer. https://doi.org/10.1007/0-387-24530-8_3

Gal, I., Ginsburg, L., \& Schau, C. (1997). Monitoring attitudes and beliefs in statistics education. In I. Gal \& J. B. Garfield (Eds.), The assessment challenge in statistics education (pp. 37-51). IOS Press.

Gal, I., \& Ograjenšek, I. (2017). Official Statistics and Statistics Education: Bridging the Gap. Journal of Official Statistics, 33(1), 79-100. https:/ / doi.org/10.1515/jos-2017-0005

Gardner, H. (1993). Multiple intelligences: The theory in practice. New York: Basic books.

Garfield, J., \& Ben-Zvi, D. (2008). Developing students' statistical reasoning: Connecting research and teaching practice. New York: Springer Verlag.

Giordano, B., \& Roller, E. (2003). A Comparison of City Region Dynamics in the UK, Spain and Italy: More Similarities than Differences? Regional Studies, 37(9), 911-927. https:/ / doi.org/10.1080/0034340032000143913

Guàrdia-Olmos, J., Freixa, M., Peró, M., Turbany, J., Cosculluela, A., Barrios, M., \& Rifà, X. (2006). Factors Related to the Academic Performance of Students in the Statistics Course in Psychology. Quality E Quantity, 40(4), 661-674. https: / / doi.org/10.1007/s11135-005-2072-7

Hamilton, L. S. (2009). Using PISA Data to Measure School and System Characteristics and Their Relationships with Student Performance in Science. Retrieved from https:/ / www.researchgate.net/ publication/ 255653141

Heckhausen, H., \& Leppmann, P. K. (1991). Motivation and action. Springer-Verlag Publishing.

Herrera, A.-N., \& Gómez, J. (2008). Influence of equal or unequal comparison group sample sizes on the detection of differential item functioning using the Mantel-Haenszel and logistic regression techniques. Quality $\mathcal{E}$ Quantity, 42(6), 739-755. https:/ / doi.org/10.1007/s11135-006-9065-Z

Jackson, S., Kleitman, S., Howie, P., \& Stankov, L. (2016). Cognitive abilities, monitoring confidence, and control thresholds. Explain individual differences in heuristics and biases. Frontiers in Psychology, 7. https://doi.org/10.3389/fpsyg.2016.01559 
Jones, G. (2005). Exploring probability in school: Challenges for teaching and learning. New York: Springer.

Kastberg, D., Ying Chan, J., \& Murray, G. (2016). Performance of U.S. 15-Year-Old Students in Science, Reading, and Mathematics Literacy in an International Context-First Look at PISA 2015.

Lai, K., Cabrera, J., Vitale, J. M., Madhok, J., Tinker, R., \& Linn, M. C. (2016). Measuring Graph Comprehension, Critique, and Construction in Science. Journal of Science Education and Technology, 1-17. https:/ / doi.org/10.1007/s10956-016-9621-9

Lalonde, R. N., \& Gardner, R. C. (1993). Statistics as a second language? A model for predicting performance in psychology students. Canadian Journal of Behavioural Science, 25(1), 108-125. https:/ / doi.org/10.1037/h0078792

López-Justicia, M. D., Hernández, C. M., Fernández Jiménez, C., Polo Sánchez, T., \& López Chacón, H. (2008). Características formativas y socioafectivas del alumnado de nuevo ingreso en la Universidad. Revista Electrónica de Investigación Psicoeducativa, 14(6 (1)), 95-116.

Macher, D., Paechter, M., Papousek, I., Ruggeri, K., Freudenthaler, H. H., \& Arendasy, M. (2013). Statistics anxiety, state anxiety during an examination, and academic achievement. British Journal of Educational Psychology, 83(4), 535-549. https:// doi.org/10.1111/j.2044-8279.2012.02081.x

Martins, L., \& Veiga, P. (2010). Do inequalities in parents' education play an important role in PISA students' mathematics achievement test score disparities? Economics of Education Review, 29(6), 1016-1033. https://doi.org/10.1016/j.econedurev.2010.05.001

Moro, R., Bodanza, G. A., \& Freidin, E. (2011). Sets or frequencies? How to help people solve conditional probability problems. Journal of Cognitive Psychology, 23(7), 843-857. https:/ / doi.org/10.1080/20445911.2011.579072

Morsanyi, K., Primi, C., Chiesi, F., \& Handley, S. (2009). The effects and side-effects of statistics education: Psychology students' (mis-) conceptions of probability. Contemporary Educational Psychology, 34(3), 210-220. https:/ / doi.org/10.1016/j.cedpsych.2009.05.001

Onwuegbuzie, A. J. (1995). Statistics test anxiety and female students. Psychology of Women Quarterly, 19(3), 413418. https:/ / doi.org/10.1111/j.1471-6402.1995.tb00083.x

Onwuegbuzie, A. J., \& Seaman, M. A. (1995). The effect of time constraints and statistics test anxiety on test performance in a statistics course. The Journal of Experimental Education, 63(2), 115-124. https:/ / doi.org/10.1080/00220973.1995.9943816

Oppedisano, V., \& Turati, G. (2015). What are the causes of educational inequality and of its evolution over time in Europe? Evidence from PISA. Education Economics, 23(1), 3-24. https:/ / doi.org/10.1080/09645292.2012.736475

Penna, M. P., Agus, M., Peró-Cebollero, M., Guàrdia-Olmos, J., \& Pessa, E. (2014). The use of imagery in statistical reasoning by university undergraduate students: a preliminary study. Quality and Quantity, 48(1), 173-187. https:/ / doi.org/10.1007/s11135-012-9757-5

Primi, C., \& Chiesi, F. (2016). Statistics anxiety: A mediator in learning probability. In 13th International Congress on Mathematical Education (pp. 1-7). Hamburg, July 24-31, 2016.

Richardson, M., Abraham, C., \& Bond, R. (2012). Psychological correlates of university students' academic performance: a systematic review and meta-analysis. Psychological Bulletin, 138(2), 353. https://doi.org/10.1037/a0026838

Schau, C., Stevens, J., Dauphinee, T. L., \& Del Vecchio, A. (1995). The Development and Validation of the Survey of Attitudes toward Statistics. Educational and Psychological Measurement, 55(5), 868-875. https:/ / doi.org/10.1177/0013164495055005022

Spain: Overview - Eurydice. (2017). Retrieved on July 20, 2017, from https://webgate.ec.europa.eu/fpfis/mwikis/eurydice/index.php/Spain:Overview

Stankov, L. (2013). Noncognitive predictors of intelligence and academic achievement: An important role of confidence. Personality and Individual Differences, 55(7), 727-732. https:/ / doi.org/10.1016/j.paid.2013.07.006

Stankov, L., Morony, S., \& Lee, Y. P. (2014). Confidence: the best non-cognitive predictor of academic achievement? Educational Psychology, 34(1), 9-28. https:/ / doi.org/10.1080/01443410.2013.814194

Thurstone, L. L., \& Thurstone, T. G. (1981). PMA: abilità mentali primarie: manuale di istruzioni - Batteria fattoriale delle abilità mentali primarie. Firenze: Organizzazioni Speciali.

Thurstone, L. L., \& Thurstone, T. G. (1987). TEA - tests de aptitudes escolares : manual (Vol. 5a). Madrid: Tea.

Triventi, M., \& Trivellato, P. (2009). Participation, performance and inequality in Italian higher education in the 20th century: Evidence from the Italian Longitudinal Household Survey. Higher Education, 57(6), 681-702. https:/ / doi.org/10.1007/s10734-008-9170-0 
van Ginkel, G., Oolbekkink, H., Meijer, P. C., \& Verloop, N. (2016). Adapting mentoring to individual differences in novice teacher learning: the mentor's viewpoint. Teachers and Teaching, 22(2), 198-218. https:/ / doi.org/10.1080/13540602.2015.1055438

Vigil-Colet, A., Lorenzo-Seva, U., \& Condon, L. (2008). Development and validation of the statistical anxiety scale. Psicothema, 20(1), 174-180.

Wells, J. B., Christiansen, M. H., Race, D. S., Acheson, D. J., \& MacDonald, M. C. (2009). Experience and sentence processing: statistical learning and relative clause comprehension. Cognitive Psychology, 58(2), $250-71$. https:/ / doi.org/10.1016/j.cogpsych.2008.08.002

Williams, A. (2014). An Exploration of Preference for Numerical Information in Relation to Math Self-Concept and Statistics Anxiety in a Graduate Statistics Course. Journal of Statistics Education, 22(1).

Wu, C. M., Meder, B., Filimon, F., \& Nelson, J. D. (2017). Asking better questions: How presentation formats influence information search. Journal of Experimental Psychology: Learning, Memory, and Cognition, 43(8), 12741297. https:/ / doi.org/10.1037/xlm0000374

Yamagishi, K. (2003). Facilitating normative judgments of conditional probability: Frequency or nested sets? Experimental Psychology, 50(2), 97-106. https:/ / doi.org/10.1026//1618-3169.50.2.97

\section{http://www.ejmste.com}

